https://nv.nltu.edu.ua

https://doi.org/10.36930/40300521

Article received 03.11.2020 $\mathrm{p}$.

Article accepted $18.10 .2020 \mathrm{p}$.

$@$ Correspondence author

UDC 004.42:536.24

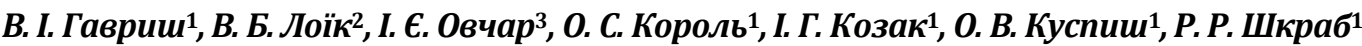 \\ ${ }^{1}$ Начіональний університет "Львівська політехніка", м. Львів, Украӥна \\ 2 Львівський держсавний університет безпеки життєдіяльності, м. Львів, Україна \\ ${ }^{3}$ Івано-Франківський національний технічний університет нафти і газу, м. Івано-Франківськ, Украйна
}

\title{
МАТЕМАТИЧНІ МОДЕЛІ ВИЗНАЧЕННЯ ТЕМПЕРАТУРНИХ РЕЖИМІВ У ЕЛЕМЕНТАХ ЛІТІЙ-ІОННИХ АКУМУЛЯТОРНИХ БАТАРЕЙ
}

\begin{abstract}
Удосконалено раніше розроблені та наведено нові математичні моделі визначення та аналізу температурних режимів в окремих елементах літій-іонних акумуляторних батарей, які геометрично описано ізотропними півпростором і простором із внутрішнім джерелом тепла циліндричної форми. Також розглянуто випадки для півпростору, коли тепловиділяючий циліндр є тонким, а для простору, коли він $є$ термочутливим. Для цього з використанням теорії узагальнених функцій у зручній формі записано вихідні диференціальні рівняння теплопровідності з крайовими умовами. Для розв'язування отриманих крайових задач теплопровідності використано інтегральне перетворення Ганкеля і внаслідок отримано аналітичні розв'язки в зображеннях. До цих розв'язків застосовано обернене інтегральне перетворення Ганкеля, яке дало змогу отримати остаточні аналітичні розв'язки вихідних задач. Отримані аналітичні розв'язки подано у вигляді невласних збіжних інтегралів. Для визначення числових значень температури в наведених конструкціях, а також аналізу теплообміну в елементах літій-іонних батарей, зумовленого різними температурними режимами завдяки нагріванню внутрішніми джерелами тепла, зосередженими в об'ємі циліндра, розроблено обчислювальні програми. Із використанням цих програм наведено графіки, які відображають поведінку кривих, побудованих із використанням числових значень розподілу температури залежно від просторових радіальної та аксіальної координат. Отримані числові значення температури свідчать про відповідність наведених математичних моделей визначення розподілу температури реальному фізичному процесу. Програмні засоби також дають змогу аналізувати середовища із внутрішнім нагріванням, зосередженим у просторових фігурах правильної геометричної форми, щодо їх термостійкості. Як наслідок, стає можливим її підвищити, визначити допустимі температури нормальної роботи літій-іонних батарей, захистити їх від перегрівання, яке може спричинити руйнування не тільки окремих елементів, а й всієі конструкції.
\end{abstract}

Ключові слова: літій-іонні акумуляторні батареї; теплопровідність; конвективний теплообмін; температурне поле; термочутливе середовище; тепловіддача.

\section{Вступ}

Розвиток сучасних технологій спонукає до швидкого росту та розвитку виробництва електричних і гібридних електромобілів, які на ринку витісняють автомобілі 3 двигунами внутрішнього згоряння. Одночасно з приходом нових технологій зростає кількість загроз і небезпек, на які повинні реагувати аварійно-рятувальні підрозділи. Подібна небезпека виникає в електромобілях, які використовують підрозділи пожежної охорони, внаслідок використання акумуляторних батарей вели- кої ємності. Основні виробники електрокарів у конструкції акумуляторних батарей використовують літійіонні акумулятори, які працюють із використанням графітних електродів і відрізняються тільки типом елементів живлення та їх розміщенням у самій акумуляторній батареї. У цьому випадку варто зазначити, що графіт під час нагрівання мало розширюється, має високу теплопровідність, що приблизно у два рази є вищою за теплопровідність вольфрамових сплавів і тому є стійким проти термічних ударів. А щодо форми, то найпо-

\section{Інформація про авторів:}

Гавриш Василь Іванович, д-р техн. наук, професор, кафедра програмного забезпечення.

Email: gavryshvasyl@gmail.com; https://orcid.org/0000-0003-3092-2279

Лоїк Василь Богданович, канд. техн. наук, доцент, кафедра пожежної тактики та аварійно-рятувальних робіт. Email: v.loik1984@gmail.com; http://orcid.org/0000-0002-3772-1640

Овчар Ігор Євгенович, канд. фіз.-мат. наук, доцент, кафедра вищої математики.

Email: igor.ovchar21@gmail.com; https://orcid.org/0000-0003-0477-0742

Король Олександр Сергійович, ст. викладач, кафедра фізичного виховання. Email: korol_lofkk@i.ua

Козак Іван Герасимович, ст. викладач, кафедра фізичного виховання. Email: gavryshvasyl@gmail.com

Кушпис Олександр Володимирович, викладач, кафедра фізичного виховання. Email: gavryshvasyl@gmail.com

Шкраб Роман Романович, асистент, кафедра програмного забезпечення. Email: ikni.pz@gmail.com

Цитування за ДСтУ: Гавриш В. І., Лоїк В. Б., Овчар І. Є., Король О. С., Козак І. Г., Куспиш О. В., Шкраб Р. Р. Математичні моделі визначення температурних режимів у елементах літій-іонних акумуляторних батарей. Науковий вісник НлТУ України. 2020, т. 30, № 5. C. 128-134.

Citation APA: Havrysh, V. I., Loik, V. B., Ovchar, I. Ye., Korol, O. S., Kozak, I. G., Kuspish, O. V., \& Shkrab, R. R. (2020). Mathematical models for determining temperature regimes in the elements of lithium-ion batteries. Scientific Bulletin of UNFU, 30(5), $128-134$. https://doi.org/10.36930/40300521 
ширенішими елементами живлення зараз $є$ елементи циліндричної форми, які використовують зокрема в електромобілях компанії Tesla. Літій-іонні батареї мають низку переваг, зокрема термін функціонування та можливість їх швидкого зарядження. Але поряд із їх великими перевагами існує низка недоліків, які несуть потенційну пожежну небезпеку як транспортним засобам, так і персоналу їх обслуговування. Це зумовлено тим, що в середині елементів живлення міститься електроліт, який легко займається і $є$ причиною незворотної термічної реакції, що внаслідок приводить до виділення легкозаймистих і токсичних газів, а в деяких випадках і до руйнування елементів живлення. Незворотна термічна реакція виникає внаслідок нестабільного режиму роботи елементів живлення, спричиненого коротким замиканням, перегріванням, перезарядженням і механічними пошкодженнями. 3 огляду на це доволі актуальною постає задача розроблення математичних моделей процесу нагрівання літій-іонних елементів живлення, які враховують їх геометричну форму та хімічний склад. Створення таких математичних моделей у подальшому дає змогу визначати необхідні показники температури та виконувати розрахунки виділеної кількості теплоти, не проводячи дорогих експериментів, а також для розроблення різноманітних нових варіантів елементів живлення 3 покращеними конструкційними параметрами.

Об'єкт дослідження - процеси теплообміну в середовищах із внутрішнім нагріванням, зосередженим в об'ємах фігур правильної геометричної форми.

Предмет дослідження - засоби розроблення лінійних і нелінійних математичних моделей процесу теплообміну та методи визначення аналітичних розв'язків відповідних крайових задач математичної фізики.

Мета роботи - розроблення математичних моделей для визначення та аналізу температурних режимів у окремих елементах літій-іонних акумуляторних батарей, які дають змогу встановити допустимі температури нормальної роботи.

Для досягнення зазначеної мети визначено такі ocновні завдання дослідження:

- проаналізувати останні дослідження та публікації;

- навести об'єкт дослідження та його математичні моделі;

- виконати та проаналізувати числові результати дослідження;

- сформулювати основні висновки та вказати оцінку їх достовірності.

Наукова новизна отриманих результатів дослідження - 3 використанням узагальнених функцій у наочній формі записано остаточні диференціальні рівняння теплопровідності з крайовими умовами, що дало змогу застосувати до них інтегральне перетворення та отримати аналітичні розв'язки наведених крайових задач.

Практична значущістьь результатів дослідження розроблено обчислювальні програми, які дають змогу визначити числові значення температури у відповідних конструкціях, а також проаналізувати теплообмін у елементах турбогенераторів, зумовленого різними температурними режимами завдяки нагріванню внутрішніми джерелами тепла, зосередженими в об'ємі циліндра. Отримані числові значення температури свідчать про відповідність наведених математичних моделей визначення розподілу температури реальному фізичному процесу.

Аналіз останніх досліджень та публікацій. Визначення температурних режимів як в однорідних, так і не- однорідних конструкціях привертає увагу багатьох дослідників $[1,2,4,11,15,17]$. У працях $[3,6,7]$ удосконалено наявні та розроблено нові підходи до створення математичних моделей аналізу теплообміну між кусково-однорідними конструкціями та навколишнім середовищем і методів розв'язування лінійних і нелінійних крайових задач для кусково-однорідних середовищ. Розглянуто дво- та тривимірні моделі, що містять рівняння, коефіцієнти яких $є$ функціями теплофізичних властивостей фаз і геометричної структури. Наведено методи визначення аналітичних та аналітично-числових розв'язків крайових задач теплопровідності. Досліджено та проаналізовано теплообмінні процеси в однорідних та шаруватих конструкціях із чужорідними внесеннями канонічної форми. Розроблено математичну модель для дослідження температурного поля, спричиненого ротаційним зварюванням металів за допомого тертя. Для цього сформовано осесиметричну нелінійну крайову задачу теплопровідності для двох кругових циліндрів 3 одночасним урахуванням теплоутворення внаслідок тертя та від пластичного деформування. Прийнято, що коефіцієнт тертя, межа пластичності і теплофізичні властивості матеріалів зразків змінюються 3 підвищенням температури. Числовий розв'язок задачі отримано методом скінченних елементів. Обчислення виконано для двох зразків, виготовлених зі сталі AISI 1040. Виявлено, що фрикційне теплоутворення відчутніше, порівняно 3 нагріванням від пластичного деформування, впливає на максимальну температуру поверхні контакту. Встановлено емпіричні залежності температури від параметра, що характеризує частку кожного iз двох зазначених механізмів теплоутворення в загальній кількості генерованого тепла. Верифіковано розрахункову модель порівнянням обчислених значень температури 3 відповідними експериментальними [14]. Розроблено математичну модель для визначення нестаціонарного температурного поля в багатошаровій термочутливій пластині за різних умов нагрівання. Застосовано до сформульованої нелінійної крайової задачі перетворення Гудмена й отримано методом прямих 3 використанням інтегро-інтерполяційного методу іiї напівдискретний аналог у вигляді задачі Коші для системи нелінійних звичайних диференціальних рівнянь. Чисельно за допомогою формул диференціювання назад, задавши температурні залежності для теплофізичних параметрів шарів пластини, розв'язано задачу Коші для системи нелінійних звичайних диференціальних рівнянь у двошаровій пластині. Приріст температури визначено через змінну Гудмена за формулами оберненої інтерполяції [5].

\section{Результати дослідження та їх обговорення}

Математичні моделі об'єкта дослідження. У роботі [8] розроблено математичну модель визначення температурного поля та аналізу температурних режимів у літій-іонних акумуляторних батареях, конструкцію вузлів яких геометрично описано шаруватою структурою. Наведемо ще низку математичних моделей теплообміну, які дають змогу визначати температурні поля в окремих елементах літій-іонних акумуляторних батарей i встановлювати допустимі значення температури для їх нормальної роботи.

1. Розглянемо ізотропний півпростір, в об'ємі $2 \pi R^{2} h$ циліндра якого зосереджені рівномірно розподілені 
внутрішні джерела тепла 3 потужністю $q_{0}=$ const, віднесений до циліндричної системи координат (Orpz) iз початком у центрі циліндра. На поверхні $z=-h-l$ півпростору задано умову конвективного теплообміну із навколишнім середовищем за законом Ньютона, температура якого є такою, що дорівнює $t_{c}=$ const (рис. 1).

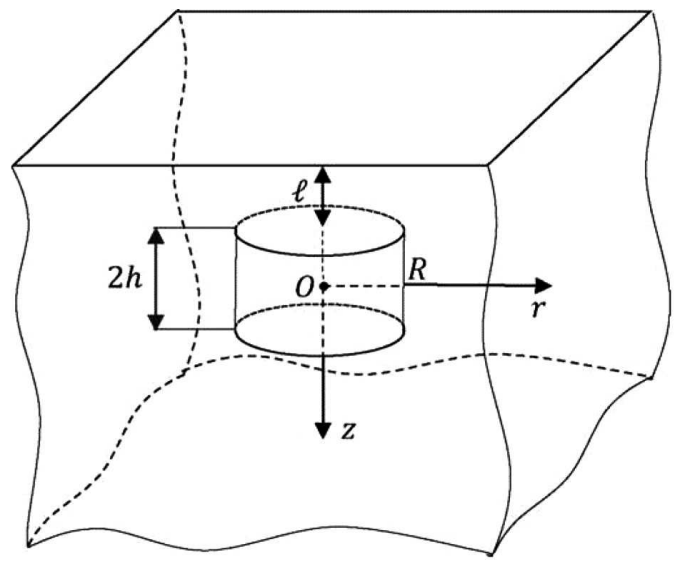

Рис. 1. Ізотропний півпростір із циліндричним джерелом тепла

Для визначення стаціонарного температурного поля $t(r, z)$ у наведеному середовищі використаємо рівняння теплопровідності $[12,16]$

$$
\lambda \Delta t=-q_{0} S_{-}(R-r) N(z)
$$

3 крайовими умовами:

$$
\left.\lambda \frac{\partial t}{\partial z}\right|_{z=-h-l}=\alpha_{z}\left(\left.t\right|_{z=-h-l}-t_{c}\right),\left.\quad t\right|_{r, z \rightarrow \infty}=t_{c}
$$

де: $\lambda$ - коефіцієнт теплопровідності півпростору; $\alpha_{z}-$ коефіцієнт тепловіддачі з поверхні $z=-h-l$ півпростору; $\Delta=\frac{1}{r} \frac{\partial}{\partial r}\left(r \frac{\partial}{\partial r}\right)+{\frac{\partial}{\partial z^{2}}}^{2}-$ оператор Лапласа в циліндричній системі координат; $N(z)=S_{-}(z+h)-S_{+}(z-h)$; $S_{ \pm}(\zeta)=\left\{\begin{array}{l}1, \quad \zeta>0, \\ 0,5 \pm 0,5, \quad \zeta=0, \quad-\text { асиметричні одиничні функції } \\ 0, \quad \zeta<0,\end{array}\right.$ [13]. До співвідношень (1), (2) застосовуємо інтегральне перетворення Ганкеля за просторовою координатою $r$. Тоді отримаємо звичайне диференціальне рівняння зі сталими коефіцієнтами

$$
\frac{d^{2} \bar{\theta}}{d z^{2}}-\xi^{2} \bar{\theta}=-\frac{q_{0} R}{\lambda \xi} I_{1}(R \xi) N(z)
$$

3 крайовими умовами

$$
\left.\lambda \frac{\partial \bar{\theta}}{\partial z}\right|_{z=-h-l}=\left.\alpha_{z} \bar{\theta}\right|_{z=-h-l},\left.\bar{\theta}\right|_{z \rightarrow \infty}=0
$$

де: $\theta(r, z)=t(r, z)-t_{c} ; \bar{\theta}(z)=\int_{0}^{\infty} r I_{0}(r \xi) \theta(r, z) d r \quad$ - трансформанта температури $\theta(r, z) ; \xi$ - параметр інтегрального перетворення, $J_{v}(x)=\sum_{n=0}^{\infty}(-1)^{n} \frac{(x / 2)^{v+2 n}}{n !(v+n) !}-$ функція Бесселя першого роду $v$-го порядку.

Загальний розв'язок рівняння (3) знайдемо методом варіації сталих у такому вигляді

$$
\begin{gathered}
\bar{\theta}(z)=c_{1} e^{\xi z}+c_{2} e^{-\xi z}+\frac{q_{0} R}{\lambda \xi^{3}} I_{1}(R \xi)[N(z)- \\
\left.-\operatorname{ch} \xi(z+h) S_{-}(z+h)+\operatorname{ch} \xi(z-h) S_{+}(z-h)\right],
\end{gathered}
$$

де $c_{1}, c_{2}$ - сталі інтегрування, які визначимо із використанням крайових умов (4).

Тоді отримаємо частковий розв'язок задачі (3), (4)

$$
\begin{aligned}
& \bar{\theta}(z)=\frac{q_{0} R}{\lambda \xi^{3}} I_{1}(R \xi)\left\{\operatorname{sh} \xi h\left[e^{\xi z}+\frac{\lambda \xi-\alpha_{z}}{\lambda \xi+\alpha_{z}} e^{-\xi(z+h+l)}\right]+\right. \\
& \left.+N(z)-\operatorname{ch} \xi(z+h) S_{-}(z+h)+\operatorname{ch} \xi(z-h) S_{+}(z-h)\right\} .
\end{aligned}
$$

Застосувавши обернене інтегральне перетворення Ганкеля до співвідношення (5), отримаємо вираз для шуканої температури

$$
\begin{gathered}
\theta(r, z)=\frac{q_{0} R}{\lambda} \int_{0}^{\infty} \frac{I_{0}(r \xi)}{\xi^{2}} I_{1}(R \xi)\left\{\operatorname{sh} \xi h\left[e^{\xi z}+\frac{\lambda \xi-\alpha_{z}}{\lambda \xi+\alpha_{z}} e^{-\xi(z+h+l)}\right]+\right. \\
\left.+N(z)-\operatorname{ch} \xi(z+h) S_{-}(z+h)+\operatorname{ch} \xi(z-h) S_{+}(z-h)\right\} d \xi
\end{gathered}
$$

яким повністю виражено температурне поле в ізотропному півпросторі 3 тепловіддачею, що нагрівається джерелом тепла циліндричної форми.

Для випадку, коли на поверхні $z=-h-l$ півпростору задано умову $t=t_{c}=$ const , розв'язок крайової задачі буде таким:

$$
\begin{gathered}
\theta(r, z)=\frac{q_{0} R}{\lambda} \int_{0}^{\infty} \frac{I_{0}(r \xi)}{\xi^{2}} I_{1}(R \xi)\left\{\operatorname{sh} \xi h\left[e^{\xi z}-e^{-\xi(z+2(\mathrm{~h}+1))}\right]+\right. \\
\left.+N(z)-\operatorname{ch} \xi(z+h) S_{-}(z+h)+\operatorname{ch} \xi(z-h) S_{+}(z-h)\right\} d \xi .
\end{gathered}
$$

Припустимо, що півпростір нагрівається тепловим потоком, поверхнева густина якого дорівнює $q_{0}=$ const , зосередженим у крузі з радіусом $R$ на поверхні півпростору. Тоді рівняння теплопровідності для цього випадку запишемо у вигляді

$$
\frac{1}{r} \frac{\partial}{\partial r}\left(r \frac{\partial}{\partial r}\right)+\frac{\partial^{2} t}{\partial z^{2}}=0
$$

3 такими крайовими умовами:

$$
\left.\lambda \frac{\partial t}{\partial z}\right|_{z=0}=-q_{0} S_{-}(R-r),\left.\quad t\right|_{z \rightarrow \infty}=t_{c},\left.\quad t\right|_{r \rightarrow \infty}=t_{c} .
$$

Застосуємо до задачі (8), (9) інтегральне перетворення Ганкеля за просторовою координатою $r$. Тоді отримаємо звичайне диференціальне рівняння зі сталими коефіцієнтами

$$
\frac{d^{2} \bar{\theta}}{d z^{2}}-\xi^{2} \bar{\theta}=0
$$

3 крайовими умовами:

$$
\left.\lambda \frac{\partial \bar{\theta}}{\partial z}\right|_{z=0}=-\frac{q_{0} R}{\xi} I_{1}(R \xi),\left.\quad \bar{\theta}\right|_{z \rightarrow \infty}=0 .
$$

Частковий розв'язок крайової задачі (10), (11) знайдемо у такому вигляді

$$
\bar{\theta}(z)=\frac{q_{0} R}{\lambda \xi^{2}} e^{-\xi z} I_{1}(R \xi)
$$

Застосувавши обернене інтегральне перетворення Ганкеля до співвідношення (12), отримаємо вираз для шуканої температури $\theta(r, z)$ у вигляді

$$
\theta(r, z)=\frac{q_{0} R}{\lambda} \int_{0}^{\infty} \frac{I(R \xi) I_{0}(r \xi)}{\xi} e^{-\xi z} d \xi
$$

Отже, за допомогою формули (13) описано температурне поле в ізотропному півпросторі, який нагрівається локально зосередженим на поверхні півпростору тепловим потоком.

2. Розглянемо випадок, коли відстань $l$ від поверхні циліндра до поверхні півпростору є набагато більшою 
за висоту $h$ та радіус $R(l \gg h, l \gg R)$ тепловиділяючого циліндра (рис. 2). Із урахуванням цього рівняння теплопровідності (1) запишемо у вигляді

$$
\lambda \Delta t=-q_{0} S_{-}(R-r) \delta(z)
$$

3 крайовими умовами:

$$
\left.\lambda \frac{\partial t}{\partial z}\right|_{z=-l}=\alpha_{z}\left(t_{z=-l}-t_{c}\right),\left.\quad t\right|_{r, z \rightarrow \infty}=t_{c}
$$

де: $\delta(z)=\frac{d S(z)}{d z}-$ дельта функція Дірака

$$
S(z)=\left\{\begin{array}{l}
1, \quad z>0, \\
0,5, \quad z=0,- \text { симетрична одинична функція. } \\
0, \quad z<0,
\end{array}\right.
$$

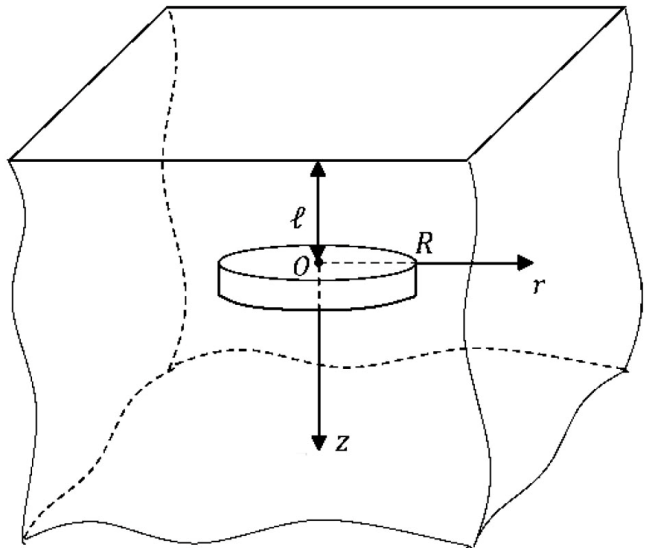

Рис. 2. Ізотропний півпростір із джерелом тепла, зосередженим у тонкому циліндрі

До крайової задачі (14), (15) застосуємо інтегральне перетворення Ганкеля за просторовою координатою $r$. Тоді отримаємо звичайне диференціальне рівняння зі сталими коефіцієнтами

$$
\frac{d^{2} \bar{\theta}}{d z^{2}}-\xi^{2} \bar{\theta}=-\frac{q_{0} R}{\lambda \xi} I_{1}(R \xi) \delta(z)
$$

та крайові умови:

$$
\left.\lambda \frac{\partial \bar{\theta}}{\partial z}\right|_{z=-l}=\left.\alpha_{z} \bar{\theta}\right|_{z=-l},\left.\bar{\theta}\right|_{z \rightarrow \infty}=0 .
$$

Загальний розв'язок рівняння (16) знайдемо методом варіації сталих у вигляді

$$
\bar{\theta}(z)=c_{1} e^{\xi z}+c_{2} e^{-\xi z}-\frac{q_{0} R}{\lambda \xi^{2}} I_{1}(R \xi) \operatorname{sh} \xi z S(z) .
$$

Сталі інтегрування $c_{1}, c_{2}$ визначимо, використавши крайові умови (17). Тоді отримаємо частковий розв'язок задачі (16), (17)

$$
\bar{\theta}(z)=\frac{q_{0} R}{\lambda \xi^{2}} I_{1}(R \xi)\left[\frac{1}{2}\left(e^{\xi z}+\frac{\lambda \xi-\alpha_{z}}{\lambda \xi+\alpha_{z}} e^{-\xi(z+2 h)}\right)-\operatorname{sh} \xi S(z)\right] .
$$

Застосувавши обернене інтегральне перетворення Ганкеля до співвідношення (18), отримаємо вираз для шуканої температури $\theta(r, z)$ у вигляді

$$
\begin{gathered}
\theta(r, z)= \\
=\frac{q_{0} R}{\lambda} \int_{0}^{\infty} \frac{I_{1}(R \xi) I_{0}(r \xi)}{\xi}\left[\frac{e^{\xi z}}{2}-\operatorname{sh} \xi z S(z)+\frac{\lambda \xi-\alpha_{z}}{\lambda \xi+\alpha_{z}} \frac{e^{-\xi(z+2 l)}}{2}\right] d \xi,
\end{gathered}
$$

яким описано температурне поле в ізотропному півпросторі, що нагрівається джерелом тепла, зосередженим у тонкому циліндрі.

3. Розглянемо ізотропний простір, в об'ємі $2 \pi R^{2} h$ циліндра якого зосереджені внутрішні джерела тепла 3 потужністю $q_{0}=$ const, віднесений до циліндричної системи координат (Or $\varphi z)$ із початком у центрі циліндра (рис. 3). Для визначення стаціонарного температурного поля $t(r, z)$ в наведеному середовищі використаємо рівняння теплопровідності (1) з крайовими умовами:

$$
\left.t\right|_{r \rightarrow \infty}=0,\left.\frac{\partial t}{\partial z}\right|_{|z| \rightarrow \infty}=0 .
$$

До даної крайової задачі застосуємо інтегральне перетворення Ганкеля за просторовою координатою $r$. Тоді отримаємо звичайне диференціальне рівняння зі сталими коефіціснтами

$$
\frac{d^{2} t}{d z^{2}}-\xi^{2} \bar{t}=-\frac{q_{0} R}{\lambda \xi} I_{1}(R \xi) N(z)
$$

та крайову умову

$$
\left.\overline{d t}\right|_{z \mapsto \infty}=0
$$

де $\bar{t}(z)=\int_{0}^{\infty} r I_{0}(r \xi) t(r, z) d r \quad$ - трасформанта температури $t(r, z)$.

Загальний розв'язок рівняння (14) знайдемо методом варіації сталих у вигляді

$$
\begin{gathered}
\bar{t}(z)=c_{1} e^{\xi z}+c_{2} e^{-\xi z}+\frac{q_{0} R}{\lambda \xi^{3}} I_{1}(R \xi) . \\
\cdot\left[N(z)-\operatorname{ch} \xi(z+h) S_{-}(z+h)+\operatorname{ch} \xi(z-h) S_{+}(z-h)\right],
\end{gathered}
$$

де $c_{1}, c_{2}$ - сталі інтегрування, які визначимо із використанням крайової умови (22).

Тоді отримаємо частковий розв'язок задачі (21), (22) у такому вигляді

$$
\begin{gathered}
\bar{t}(z)=\frac{q_{0} R}{\lambda \xi^{3}} I_{1}(R \xi)\left[e^{\xi z} \operatorname{sh} h+N(z)-\right. \\
\left.-\operatorname{ch} \xi(z+h) S_{-}(z+h)+\operatorname{ch} \xi(z-h) S_{+}(z-h)\right] .
\end{gathered}
$$

Застосувавши обернене інтегральне перетворення Ганкеля до співвідношення (23), отримаємо вираз для шуканої температури

$$
\begin{aligned}
& t(r, z)=\frac{q_{0} R}{\lambda} \int_{0}^{\infty} \frac{I_{0}(r \xi)}{\xi^{2}} I_{1}(R \xi)\left\{\operatorname{sh} \xi h\left[e^{\xi z}+\frac{\lambda \xi-\alpha_{z}}{\lambda \xi+\alpha_{z}} e^{-\xi(z+h+l)}\right]+\right. \\
& \left.+N(z)-\operatorname{ch} \xi(z+h) S_{-}(z+h)+\operatorname{ch} \xi(z-h) S_{+}(z-h)\right\} d \xi
\end{aligned}
$$

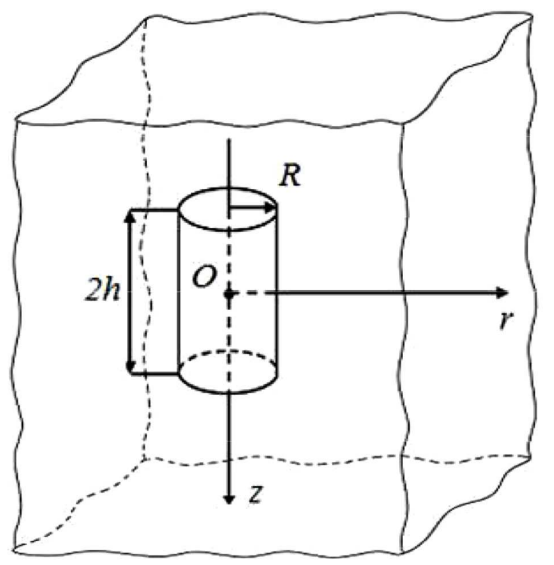

Рис. 3. Ізотропний простір із циліндричним джерелом тепла, яким виражено температурне поле в ізотропному просторі, що нагрівається джерелом тепла циліндричної форми

4. Розглянемо ізотропний термочутливий (теплофізичні параметри залежать від температури) простір, в об'ємі $2 \pi R^{2} h$ циліндра якого зосереджені внутрішні 
джерела тепла 3 потужністю $q_{0}=$ const, віднесений до циліндричної системи координат (Orez) із початком у центрі циліндра (рис. 3). Для визначення стаціонарного температурного поля в наведеному середовищі використаємо нелінійне рівняння теплопровідності $[12,16]$

$$
\frac{1}{r} \frac{\partial}{\partial r}\left(r \lambda(t) \frac{\partial t}{\partial r}\right)+\frac{\partial}{\partial z}\left(\lambda(t) \frac{\partial t}{\partial z}\right)=-q_{0} S_{-}(R-r) N(z)
$$

3 крайовими умовами:

$$
\left.\frac{\partial t}{\partial z}\right|_{|z| \rightarrow \infty}=0,\left.\frac{\partial t}{\partial r}\right|_{r \rightarrow \infty}=0,
$$

де $\lambda(t)$ - коефіцієнт теплопровідності термочутливого простору.

Введемо перетворення Кірхгофа $[12,16]$

$$
\vartheta(r, z)=\frac{1}{\lambda^{0}} \int_{0}^{t} \lambda(\zeta) d \zeta,
$$

тут $\lambda^{0}$ - опорний коефіцієнт теплопровідності простору.

Продиференціюємо вираз (27) за змінними $r$ та $z$. Тоді отримаємо співвідношення:

$$
\lambda(t) \frac{\partial t}{\partial r}=\lambda^{0} \frac{\partial \vartheta}{\partial r}, \quad \lambda(t) \frac{\partial t}{\partial z}=\lambda^{0} \frac{\partial \vartheta}{\partial z},
$$

після підстановки яких у (25), отримаємо лінійне диференціальне рівняння відносно функції $\vartheta(r, z)$

$$
\Delta \vartheta=-\frac{q_{0}}{\lambda^{0}} S_{-}(R-r) N(z) .
$$

Крайові умови для функції $\vartheta(r, z)$ із використанням співвідношень (27), (28) запишемо у вигляді

$$
\left.\vartheta\right|_{r \rightarrow \infty}=0,\left.\vartheta\right|_{|z| \rightarrow \infty}=0 .
$$

Отже, із використання перетворення Кірхгофа (27) нелінійну крайову задачу теплопровідності (25), (26) зведено до лінійної задачі (29), (30).

Застосуємо інтегральне перетворення Ганкеля за координатою $r$ до задачі (29), (30). Тоді отримаємо звичайне диференціальне рівняння зі сталими коефіцієнтами

$$
\frac{d^{2} \bar{\vartheta}}{d z^{2}}-\xi^{2} \bar{\vartheta}=-\frac{q_{0} R}{\lambda \xi} N(z) J_{1}(R \xi)
$$

3 крайовою умовою

$$
\left.\bar{\vartheta}\right|_{|z| \rightarrow \infty}=0,
$$

де $\bar{\vartheta}(z)=\int_{0}^{\infty} r J_{0}(r \xi) \vartheta(r, z) d r \quad-\quad$ трансформанта функції $\vartheta(r, z)$.

Загальний розв'язок рівняння (31) знайдемо методом варіації сталих у вигляді

$$
\begin{gathered}
\vartheta(r, z)=c_{1} e^{\xi z}+c_{2} e^{-\xi z}+\frac{q_{0} R}{\lambda^{0} \xi^{3}} J_{1}(R \xi) . \\
\cdot\left[N(z)-\operatorname{ch} \xi(z+h) S_{-}(z+h)+\operatorname{ch} \xi(z-h) S_{+}(z-h)\right] d \xi .
\end{gathered}
$$

Сталі інтегрування $c_{1}, c_{2}$ визначимо, використавши крайову умову (32). Тоді отримаємо частковий розв'язок задачі (31), (32), а саме:

$$
\begin{gathered}
\vartheta(r, z)=\frac{q_{0} R}{\lambda^{0} \xi^{3}} J_{1}(R \xi)\left[e^{\xi z} \operatorname{sh} \xi h+N(z)-\right. \\
\left.-\operatorname{ch} \xi(z+h) S_{-}(z+h)+\operatorname{ch} \xi(z-h) S_{+}(z-h)\right] d \xi .
\end{gathered}
$$

Застосувавши обернене інтегральне перетворення Ганкеля до співвідношення (33), отримаємо вираз для функції $\vartheta(r, z)$

$$
\begin{gathered}
\vartheta(r, z)=\frac{q_{0} R}{\lambda^{0}} \int_{0}^{\infty} \frac{J_{0}(r \xi)}{\xi^{2}} J_{1}(R \xi)\left[e^{\xi z} \operatorname{sh} h+N(z)-\right. \\
\left.-\operatorname{ch} \xi(z+h) S_{-}(z+h)+\operatorname{ch} \xi(z-h) S_{+}(z-h)\right] d \xi .
\end{gathered}
$$

У багатьох практичних випадках спостерігають лінійну залежність коефіцієнта теплопровідності від температури для певних інтервалів температур у вигляді співвідношення

$$
\lambda(t)=\lambda^{0}(1-k t),
$$

де $k$ - температурний коефіцієнт теплопровідності.

Тоді, із використанням виразів (27), (34) і (35), отримаємо вираз для визначення температури $t(r, z)$

$$
t(r, z)=\frac{1-\sqrt{1-2 k \vartheta(r, z)}}{k},
$$

яким повністю описано розподіл температури в термочутливому просторі 3 джерелом тепла циліндричної форми.

Аналіз числових результатів. За формулами (6), $(19),(24)$ виконано обчислення температури $t(r, z)$ і побудовано криві, які відображають їі поведінку за просторовими радіальною $r$ (рис. 4,6 ) та аксіальною $z$ (рис. 5,7$)$ координатами. Матеріалом теплоактивного елемента (катода) є графіт, значення коефіцієнта теплопровідності $\lambda$ якого дорівнює $372 \mathrm{~W} /(\mathrm{Km})$. Значення потужності внутрішніх джерел тепла $q_{0}$ дорівнює 200 $\mathrm{W} / \mathrm{m}^{3}$.

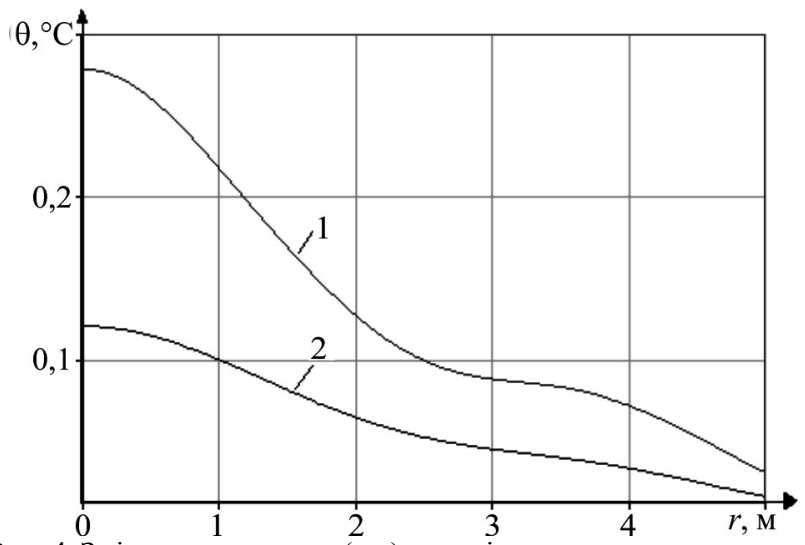

Рис. 4. Зміна температури $t(r, z)$ за радіальною координатою $\mathrm{r}$ для значення аксіальної координати $z=1 \mathrm{~m}$

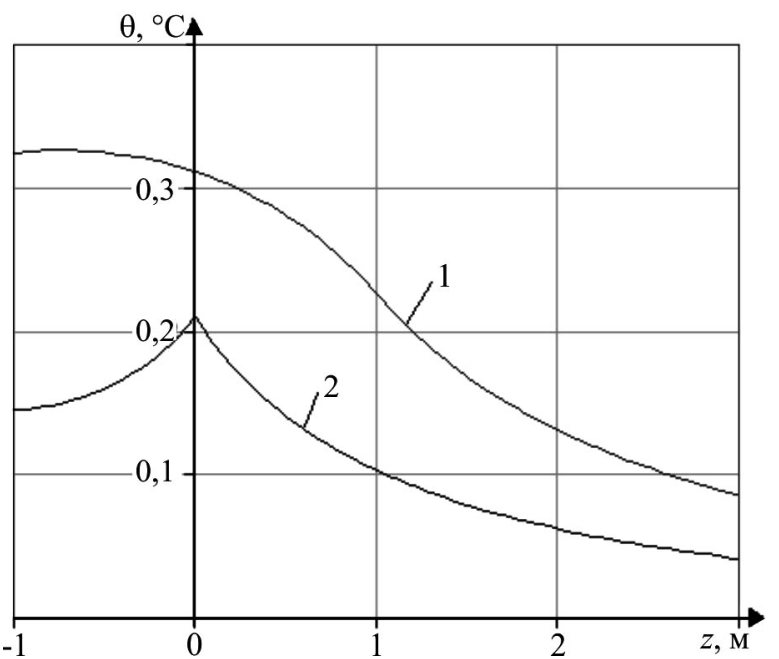

Рис. 5. Зміна температури $t(r, z)$ за аксіальною координатою z для значення радіальної координати $r=1 \mathrm{м}$

Криві 1, 2 (див. рис. 4, 5) відповідають моделям, геометричне відображення яких зображено рис. 1, 2 від- 
повідно. Рис. 6, 7 відповідають моделі, геометричне відображення якої зображено рис. 3 . Із рис. 4, 5 видно, що значення температури, визначені за двома моделями, значно відрізняються. Це свідчить про те, що хоча радіус і висота катодів циліндричної форми є малими, нехтування значеннями одного з цих параметрів приводить до великих похибок. Рис. 6, 7 ілюструють теплоактивність графітних катодів, на яких температура досягає своїх найбільших значень.

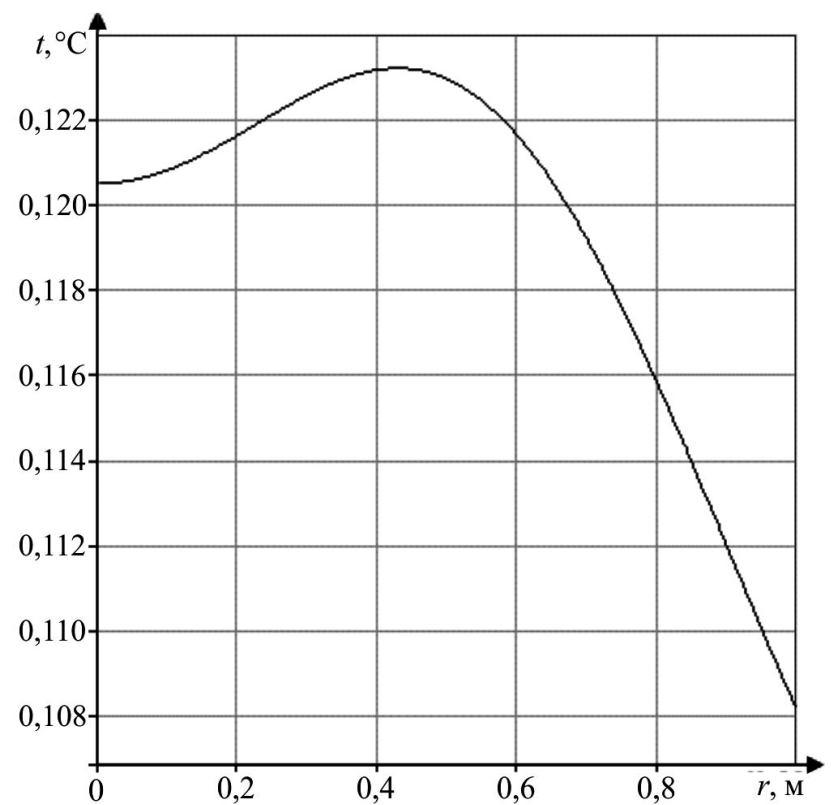

Рис. 6. Зміна температури $t(r, z)$ за радіальною координатою $\mathrm{r}$ для значення аксіальної координати $z=1 \mathrm{M}$

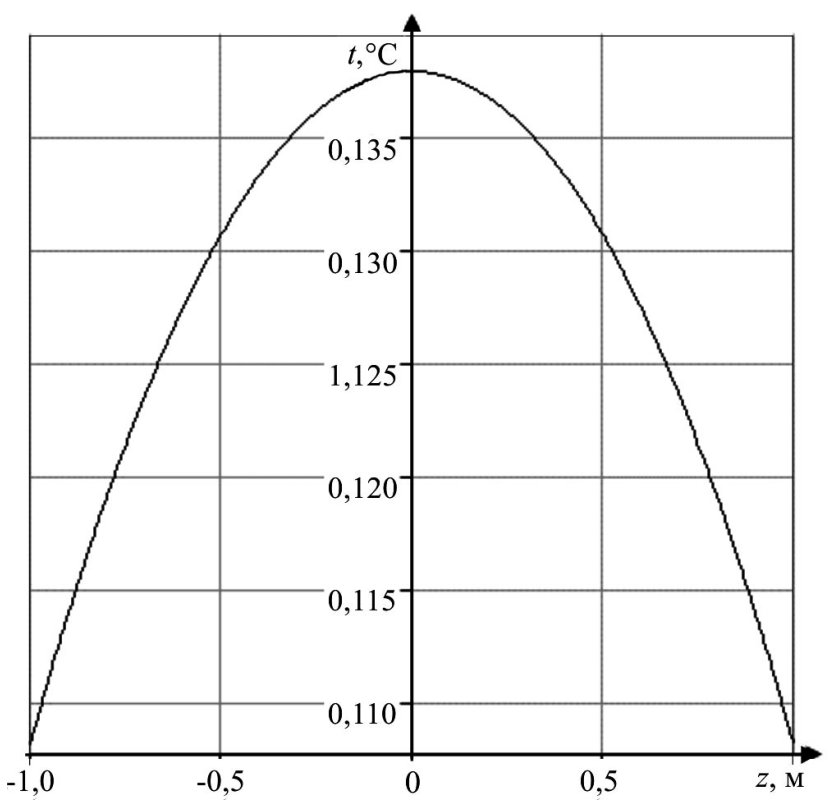

Рис. 7. Зміна температури $t(r, z)$ за аксіальною координатою z для значення радіальної координати $r=1 \mathrm{M}$

\section{Висновки}

Розроблено математичні моделі визначення та аналізу температурних режимів в окремих елементах живлення циліндричної форми літій-іонних акумуляторних батарей. Застосовано теорію узагальнених функцій, яка дала змогу в зручному вигляді описати теплоактивні елементи живлення та отримати остаточні диференціальні рівняння теплопровідності з крайовими умовами. Для випадку термочутливого елемента нелінійну математичну модель лінеаризовано за допомогою перетво- рення Кірхгофа. Внаслідок цього отримано лінійну крайову задачу відносно цього перетворення. За однією 3 просторових координат застосовано метод інтегрального перетворення й у замкнутому вигляді отримано аналітичні розв'язки крайових задач. Для термочутливого елемента нелінійну крайову задачу розв'язано для випадку лінійної залежності коефіцієнта теплопровідності конструкційного матеріалу від температури i внаслідок отримано зручну розрахункову формулу для визначення температури. Із використанням аналітичних розв'язків виконано числові розрахунки температури залежно від просторових координат і наведено їх геометричне відображення. Числовий аналіз свідчить про відповідність наведених математичних моделей реальному фізичному процесу. Отримані числові значення температури підтверджують доцільність вибору матеріалом катода графіту за рахунок високої теплопровідності та стійкості щодо термічних ударів. Наведені математичні моделі визначення та аналізу температурних режимів у елементах літій-іонних акумуляторних батарей дають змогу встановити інтервали температур, у яких відбуваються хімічні реакції з виділенням чистого кисню, що призводить до займання літій-іонних елементів.

\section{References}

1. Bayat, A., Moosavi, H., \& Bayat, Y. (2015). Thermo-mechanical analysis of functionally graded thick spheres with linearly timedependent temperature. Scientia Iranica, 22(5), 1801-1812.

2. Carpinteri, A., \& Paggi, M. (2008). Thermoelastic mismatch in nonhomogeneous beams. J. Eng. Math, 61(2-4), 371-384.

3. Gavrysh, V. I., \& Fedasjuk, D. V. (2012). Modeljuvannja temperaturnyh rezhymiv u kuskovo-odnoridnyh strukturah. Lviv: Publishing Nac. un-tu "Lvivska politehnika", 176-178.

4. Ghannad, M., \& Yaghoobi, M. P. (2015). A thermoelasticity solution for thick cylinders subjected to thermo-mechanical loads under various boundary conditions. Int. Journal of Advanced Design \& Manufacturing Technology, 8(4), 1-12.

5. Harmatii, H. Yu., Popovych, V. S., \& Krul, M. M. (2019). Vplyv termochutlyvosti materialu na neustalenyi teplovyi stan bahatosharovoi plastyny. Fizyko-khimichna mekhanika materialiv, 1, 98104. [In Ukrainian].

6. Havrysh, V. I., Baranetskiy, Ya. O., \& Kolyasa, L. I. (2018). Investigation of temperature modes in thermosensitive non-uniform elements of radioelectronic devices. Radio Electronics, Computer Sciense, Control, 3(46), 7-15.

7. Havrysh, V. I., Kolyasa, L. I., \& Ukhanka, O. M. (2019). Determination of temperature field in thermally sensitive layered medium with inclusions. Scientific Bulletin of NHU, 1, 94-100.

8. Havrysh, V. I., Loik, V. B., Korol, O. S., \& Syntlnikov, O. D. (2020). A mathematical model for determining and analyzing temperature regimes in a battery pack of electric trucks. Scientific Bulletin of UNFU, 30(1), 132-135. https://doi.org/10.36930/40300123

9. Hrytsiuk, Yu., \& Bilas, O. (2019). Visualization of Software Quality Expert Assessment. IEEE 2019 14th International Scientific and Technical Conference on Computer Sciences and Information Technologies (CSIT 2019), (Vol. 2, pp. 156-160), 17-20 September, 2019. https://doi.org/10.1109/stccsit.2019.8929778

10. Hrytsiuk, Yu., \& Grytsyuk, P., Dyak, T., \& Hrynyk, H. (2019). Software Development Risk Modeling. IEEE 2019 14th International Scientific and Technical Conference on Computer Sciences and Information Technologies (CSIT 2019), (Vol. 2, pp. 134-137), 17-20 September, 2019. https://doi.org/10.1109/stccsit.2019.8929778

11. Jabbari, M., Karampour, S., \& Eslami, M. R. (2011). Radially symmetric steady state thermal and mechanical stresses of a poro 
FGM hollow sphere. International Scholarly Research Network ISRN Mechanical Engineering, 3, 1-7. https://doi.org/10.5402/2011/305402

12. Koliano, Iu. M. (1992). Metody teploprovodnosti i termouprugosti neodnorodnogo tela. Kyiv: Scientific thought, 280 p. [In Russian].

13. Korn, G., \& Korn, T. (1977) Spravochnik po matematike dlia nauchnykh rabotnikov i inzhenerov. Moscow: Science, 640 p. [In Russian].

14. Lukashevych, A. (2019). Temperaturne pole u zoni kontaktu pid chas rotatsiinoho zvariuvannia metaliv tertiam. Physico-chemical mechanics of materials , 1, 41-46. [In Ukrainian].
15. Mohazzab, A. H., \& Jabbari, M. (2011). Two-Dimensional Stresses in a Hollow FG Sphere with Heat Source. Advanced Materials Research, 264-265, 700-705. https://doi.org/10.4028/scientific.net/amr.264-265.700

16. Podstrigach, Ia. S., Lomakin, V. A., \& Koliano, Iu. M. (1984). Termouprugost tel neodnorodnoi struktury. Moscow: Science, 350 p. [In Russian].

17. Yangian, Xu., \& Daihui, Tu. (2009). Analysis of steady thermal stress in a $\mathrm{ZrO} 2 / \mathrm{FGM} / \mathrm{Ti}-6 \mathrm{Al}-4 \mathrm{~V}$ composite ECBF plate with temperature-dependent material properties by NFEM, WASE. Int. Conference. on Informa. Eng., 2-2, 433-436.

\section{I. Havrysh', V. B. Loik' , I. Ye. Ovchar ${ }^{3}$, O. S. Korol'1, I. G. Kozak', , O. V. Kuspish', R. R. Shkrab' \\ ${ }^{1}$ Lviv Polytechnic National University, Lviv, Ukraine \\ ${ }^{2}$ Lviv State University of Life Safety, Lviv, Ukraine \\ ${ }^{3}$ Ivano-Frankivsk National Technical University of Oil and Gas, Ivano-Frankivsk, Ukraine}

\section{MATHEMATICAL MODELS FOR DETERMINING TEMPERATURE REGIMES IN THE ELEMENTS OF LITHIUM-ION BATTERIES}

New mathematical models for determining and analyzing temperature regimes in individual elements of lithium-ion batteries, which are geometrically described by isotropic half-space and space with an internal heat source of cylindrical shape, have been improved and presented. Cases are also considered for half-space, when the fuel-releasing cylinder is thin, and for space, when it is heat-sensitive. For this purpose, using the theory of generalized functions, the initial differential equations of thermal conductivity with boundary conditions are written in a convenient form. In the course of research, to solve the obtained boundary value problems of thermal conductivity, the integral Hankel transformation was used, and as a result, analytical solutions in the images were obtained. The inverse Hankel integral transformation was applied to these solutions, which made enabled obtaining the final analytical solutions of the initial problems. The obtained analytical solutions are presented in the form of improper convergent integrals. Computational programs have been developed to determine the numerical values of temperature in these structures, as well as to analyze the heat transfer in the elements of lithium-ion batteries due to different temperature regimes due to heating by internal heat sources concentrated in the cylinder volume. Using these programs, graphs are given that show the behavior of curves constructed using numerical values of the temperature distribution depending on the spatial radial and axial coordinates. The obtained numerical values of temperature indicate the correspondence of the given mathematical models for determining the temperature distribution to the real physical process. The software also allows analyzing media with internal heating concentrated in spatial figures of regular geometric shape in terms of their heat resistance. As a result, it becomes possible to increase it, to determine the allowable temperatures of normal operation of lithium-ion batteries, to protect them from overheating, which can cause the destruction of not only individual elements but also the entire structure.

Keywords: lithium-ion batteries; thermal conductivity; convective heat transfer; temperature field; thermosensitive environment; heat transfer. 